\title{
1
}

\section{SME 4.0: The Role of Small- and Medium- Sized Enterprises in the Digital Transformation}

\section{Dominik T. Matt and Erwin Rauch}

\subsection{Introduction}

In recent years, the industrial environment has been changing radically due to the introduction of concepts and technologies based on the fourth industrial revolution (Sendler 2013). At the Hanover Fair 2011 for the first time, a synonym for such a new industrial revolution was mentioned, "Industry 4.0". The focus of Industry 4.0 is to combine production, information technology and the internet. Thus, newest information and communication technologies are combined in Industry 4.0 with traditional industrial processes (BMBF 2012).

In recent years, the global economy has become a strong competitor for industry in Europe. It is no longer enough to produce faster, cheaper, and with higher quality than the competitors, defending the achieved competitive advantage. The industry needs to introduce new types of innovative and "digital" production strategies to maintain

D. T. Matt · E. Rauch $(\bowtie)$

Faculty of Science and Technology, Free University of Bozen-Bolzano, Bolzano, Italy e-mail: erwin.rauch@unibz.it 
the current competitive advantage in the long term (Manhart 2013). The fourth industrial revolution should extend to the whole production and supply chain of components, and not only, as in past revolutions, to the mechanical manufacturing process of products and the associated process organization. The development of Industry 4.0 should provide a contribution to tackle global challenges, like sustainability, resource and energy efficiency and strengthen competitiveness (Kagermann et al. 2013). In the whole production life cycle, the data exchange should be improved leading to advantages for all involved parties. More functionalities and customization options are gained for the client and more flexibility, transparency, and globalization for the supply chain (Baum 2013). In addition, the return to uniqueness should be achieved by the fourth revolution (Hartbrich 2014). Therefore, to remain competitive, the ability to respond to customer requirements quickly and flexibly and to produce high version numbers at low batch sizes, must increase (Spath et al. 2013). Industry 4.0 aims to implement highly efficient and automated manufacturing processes, usually known from mass production, also in an industrial environment, where individual and customer-specific products are fabricated according to mass customization strategies (Modrak et al. 2014). Mass customization means the production of products customized by the customer, at production costs similar to those of mass-produced products. A production, based on the principle of Industry 4.0, creates the conditions to replace traditional structures, which are based on centralized decision-making mechanisms and rigid limits of individual value-added steps. These structures are replaced by flexible reconfigurable manufacturing and logistics systems, offering interactive and collaborative decision-making mechanisms (Spath et al. 2013).

In recent years, a growing number of authors have addressed the topic of Industry 4.0 for SMEs in their scientific works (Matt et al. 2016; Bär et al. 2018; Türkeș et al. 2019). In addition, the European Commission (EC) actively supports SMEs by providing direct financial support and indirect support to increase their innovation capacity through Horizon 2020. Thus, underpinning the Europe 2020 strategy for smart and sustainable growth, the EC supports research, development and innovation projects with the aim of creating a favorable 
ecosystem for SME innovation and development. Due to their flexibility, the entrepreneurial spirit, and the innovation capabilities, SMEs have proved to be more robust than large and multi-national enterprises, as the previous financial and economic crisis showed (Matt 2007; Matt et al. 2016). Typically, SMEs are not only adaptive and innovative in terms of their products, but also in terms of their manufacturing practices. Recognizing the continuing competitive pressures, small organizations are becoming increasingly proactive in improving their business operations (Boughton and Arokiam 2000), which is a good starting point for introducing new concepts like Industry 4.0. The successful implementation of Industry 4.0 has to take place not only in large enterprises but in particular, in SMEs (Sommer 2015). Various studies point out relevant changes and potential for SMEs in the context of Industry 4.0 (Rickmann 2014). Industry 4.0 technologies offer great opportunities for the SME sector to enhance its competitiveness. SMEs are most likely to be the big winners from the shift; they are often able to implement the digital transformation more rapidly than large enterprises, because they can develop and implement new IT structures from scratch more easily (Deloitte 2015). Many small- and medium-sized companies are already focusing on digitized products in order to stand out in the market (PWC 2015). The integration of information and communication technology (ICT) and modern Industry 4.0 technologies would transform today's SME factories into smart factories with significant economic potential (Lee and Lapira 2013; Gualtieri et al. 2018).

Industry 4.0 represents a special challenge for businesses in general and for SMEs in particular. The readiness of SME adapted Industry 4.0 concepts and the organizational capability of SMEs to meet this challenge exist only in part. The smaller SMEs are, the higher the risk that they will not be able to benefit from this revolution. European SMEs are conscious about the knowledge in adaption deficits. This opens the need for further research and action plans for preparing SMEs in a technical and organizational direction (Sommer 2015). The introduction of Industry 4.0 often shows difficulties and leads to headlines such as "most SME production companies are currently not yet ready for Industry 4.0", "SMEs are missing the trends of the future" or "Industry 
4.0 has not arrived at SMEs" (Olle and Clauß 2015). Today, most SMEs are not prepared to implement Industry 4.0 concepts (Brettel et al. 2014; Orzes et al. 2018).

Therefore, special research and investigations are needed for the implementation of Industry 4.0 technologies and concepts in SMEs. SMEs will only achieve Industry 4.0 by following SME-customized implementation strategies and approaches and realizing SME-adapted concepts and technological solutions. Otherwise, actual effort for sensitization and awareness building among SMEs for Industry 4.0 will not show the expected success and results. According to this identified gap, this book considers and investigates the specific requirements of SMEs introducing Industry 4.0 and reflects on opportunities and difficulties in the digital transformation of manufacturing, logistics and organizational processes in SMEs.

\subsection{Industry 4.0 as the Fourth Industrial Revolution}

\subsubsection{Origin and Characterization of Industry 4.0}

In 2011, the German group of scientists Acatech (Deutsche Akademie der Technikwissenschaften) presented the term "Industrie 4.0" for the first time during the Hannover Fair, symbolizing the beginning of the fourth industrial revolution. The fourth industrial revolution can be described as the introduction of modern ICT in production. At the end of the eighteenth century, the first industrial revolution was initiated by inventing the machine and thus replacing muscle force. With the development of the industrial nations around the year 1870, the second industrial revolution began. The second industrial revolution was determined by the introduction of the division of labor and mass production with the help of electrical energy (Kagermann et al. 2013). The third industrial revolution referred to the multiplication of human brainpower to the same extent as human muscle power had been multiplied in the first and second industrial revolutions (Balkhausen 1978). The 
fourth industrial revolution describes a further step ahead where people, machines, and products are directly connected with each other and their environment (Plattform Industrie 4.0 2014). Figure 1.1 illustrates the fourth industrial revolutions and how each revolution has affected manufacturing.

In 2013, the working group "Arbeitskreis Industrie 4.0", consisting of representatives of industry, research, the "Forschungsunion" and associations, presented their report of recommendations for the introduction of Industry 4.0 to the government at the Hannover Fair. In addition, in 2013, the German associations BITKOM, VDMA, and ZVEI created the "Plattform Industrie 4.0" as a reference platform for a further promotion of Industry 4.0 in German politics and industry (Acatech 2013). In the first few years after the presentation and introduction of this new term, the characterization and description of Industry 4.0 varied greatly and a concrete, generally accepted definition of Industry 4.0 did not exist at that time (Bauer et al. 2014).

The main objectives of Industry 4.0 include individualization of customer requirements, flexibility, and adaptability of manufacturing and logistics systems, improved decision-making, the integration of ICT and Cyber-Physical Systems (CPS), the introduction of advanced production technologies (additive manufacturing, precise manufacturing,...), intelligent automation concepts, adapted business

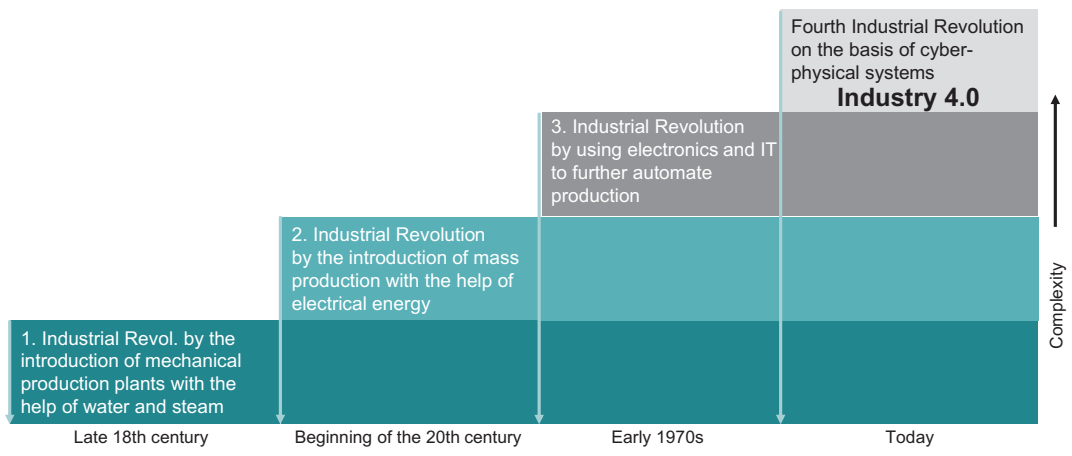

Fig. 1.1 The four industrial revolutions (Adapted from Kagermann et al. 2013) 
and organizational models as well as concepts for more sustainable production and logistics processes (Spath et al. 2013).

One of the biggest opportunities of Industry 4.0 is expected in capabilities of CPS for self-organization and self-control in so-called Cyber-Physical Production Systems (CPPS) (Monostori 2014). CPS are systems of collaborating computational entities which are in intensive connection with the surrounding physical world and its on-going processes, providing and using, at the same time, data-accessing and data processing services available on the internet. In other words, CPS can be generally characterized as "physical and engineered systems whose operations are monitored, controlled, coordinated, and integrated by a computing and communicating core" (Rajkumar et al. 2010; Laperrire and Reinhart 2014). Here the physical and digital world are combined and interact through the so-called "Internet of things" (Lee and Seshia 2016). Production data is provided of a completely new quality and with real-time information on production processes. This is possible through the comprehensive placement of production with sensors and the continuous integration of intelligent objects (Spath et al. 2013; Zhou et al. 2018). Future data models will work in real time and the production will be more transparent (Rauch et al. 2018a). An image of the production occurs as essential to new, decentralized and real-time production control. Such a production control system can cope in the future with uneven workloads in the short term and make complex decisions decentralized in a customized production environment (Spath et al. 2013; Meissner et al. 2017). With CPS, the pursuit of economies of scale as a means to reduce costs loses significance because many individual process steps can be combined more flexibly by the use of computer-based modularization of production runs. This means that with networked production technologies, an individualized production at low costs will become possible. In a traditional production system, the fullfilment of individual customer requirements is possible only by frequent change of variants or by individual execution of individual production steps, which often means higher costs because of higher production costs (BMBF 2012; Lee et al. 2015).

According to a definition of the European Commission (EC 2015), Industry 4.0 consists of a number of new and innovative technologies: 
- Information and communication technology (ICT) to digitize information and integrate systems at all stages of product creation and use (including logistics and supply), both inside companies and across company boundaries.

- Cyber-physical systems that use ICTs to monitor and control physical processes and systems. These may involve embedded sensors, intelligent robots that can configure themselves to suit the immediate product to be created, or additive manufacturing (3D printing) devices.

- Network communications including wireless and internet technologies that serve to link machines, work products, systems, and people, both within the manufacturing plant, and with suppliers and distributors.

- Simulation, modeling, and virtualization in the design of products and the establishment of manufacturing processes.

- Big data analysis and exploitation, either immediately on the factory floor, or through cloud computing.

- Digital assistance systems for human workers, including robots, augmented reality, and intelligent aid systems.

\subsubsection{Industry 4.0-A Challenge for Europe and Beyond}

The EU supports industrial change through its industrial policy and through research and infrastructure funding. Member States are also sponsoring national or trans-national initiatives. The need for investment, changing business models, data issues, legal questions of liability and intellectual property, standards, and skill mismatches are among the challenges that must be met if benefits are to be gained from new manufacturing and industrial technologies. If these obstacles can be overcome, Industry 4.0 may help to reverse the past decline in industrialization and increase total value added from manufacturing to a targeted 20\%. From 2014 to 2020, the Horizon 2020 research programme's industrial leadership pillar provides almost $€ 80$ billion for research and innovation, including support for developing key enabling technologies. In addition, "Factories of the Future" is a public-private 
partnership (PPP), launched initially under the earlier Seventh Framework Programme but continuing under Horizon 2020, that centers on advanced, smart, digital, collaborative, human-centred, and customer-focused manufacturing (EC 2015). The EU is undertaking a wide range of additional measures to support and connect national initiatives that focus on Industry 4.0 and the digitalization of industry. An overview of the European Commission shows that there are more than 30 national and regional initiatives at European level: e.g., Plattform Industrie 4.0 in Germany Catapult in UK, Fabbrica Digitale in Italy, Made Different in Belgium, Industry du Futur in France, Produktion 2030 in Sweden, Made in Denmark, Smart Industry in Netherlands, Produtech in Portugal, Industria Conectada 4.0 in Spain, Production of the Future in Austria, Průmysl 4.0 in Czech Republic, Smart Industry SK in Slovakia and many others (Plattform Industrie 4.0 2019). Also, in the new EU flagship funding program for Research and Innovation, "Horizon Europe", research for Industry 4.0 technologies, sustainable production and artificial intelligence (AI) will be addressed in the Cluster "Digital and Industry" (€15 billion) of the "Global Challenges and Industrial Competiveness pillar” (€52.7 billion) (EC 2018).

Also, in the United States, the National Science Foundation (NSF) offers funding programs for topics like Industry 4.0 technologies, in the United States better known as "Smart Manufacturing", "Smart Factory" or "Internet of Things". The Division of Civil, Mechanical and Manufacturing Innovation (CMMI) addresses research topics like additive manufacturing, CPS, computational engineering (NSF 2019). Further, the "Manufacturing USA" program, a PPP of 14 manufacturing institutes, connect member organizations, work on major research, and development collaboration projects and train people on advanced manufacturing skills (Manufacturing USA 2019).

The trend of Industry 4.0 has also reached and influenced Asian nations in their political programs and future strategies. China wants to catch up with the strongest economic powers in the world. The government has therefore drawn up the program "Made in China 2025", an ambitious plan to bring the country to the technological forefront. Where manual labor currently accounts for the majority of value added, 
automated production should dominate in the future-and turn the country into an "industrial superpower" In the Made in China 2025 strategy, the government has identified ten industries in which it wants to form leading Chinese global companies among which also are highend automation, robotics, artificial intelligence, and robotics (FAZ 2019).

Whilst China has its Made in China 2025 strategy for upgrading its manufacturing sector, India has its "Make in India" initiative to boost investments and improvements across its various industrial sectors. The Indian automotive industry occupies a prominent place within the Indian economy and therefore India is trying to remain attractive and ready for Industry 4.0 as well as the Internet of Things (Moreira 2017).

In addition, other Asian countries like Thailand are dealing with Industry 4.0. "Thailand 4.0 " is an economic model that aims to unlock the country from several economic challenges resulting from past economic development models which place emphasis on agriculture (Thailand 1.0), light industry (Thailand 2.0), and advanced industry (Thailand 3.0). The objective of Thailand 4.0 is to become attractive for innovative and value-based industry. Besides a strong emphasis on agriculture, food health and medical technologies, research topics like robotics, mechatronics, artificial intelligence, Internet of Things, and smart devices are also a focus of the Thailand 4.0 initiative (ThaiEmbDC 2019).

\subsection{The Contribution of Small and Medium Enterprises to Economic Development}

\subsubsection{The Role of SMEs in the European Economy}

Small- and medium-sized enterprises (SMEs) are a focal point in shaping enterprise policy in the European Union. The European Commission considers SMEs and entrepreneurship as key to ensuring economic growth, innovation, job creation, and social integration in the EU (Eurostat 2018). 
SMEs-defined by the European Commission as having fewer than 250 employees, an annual turnover of less than $€ 50$ million, or a balance sheet total of no more than $€ 43$ million-are the backbone of the European economy (Kraemer-Eis and Passaris). According to the SEM statistics published on the Eurostat database in 2015, there were 23.4 million SMEs in the European Union's non-financial business economy. Together they employed 91 million people and generated $€ 3934$ billion of value added. The economic contribution from SMEs was particularly apparent in Malta, Cyprus, and Estonia, with SMEs providing more than three quarters of the total value-added generated in each of their non-financial business economies. Large enterprises $(0.2 \%$ of total enterprises in EU-28) generate $43.5 \%$ of value added and count for around one third of the number of employees $(33.7 \%)$. Two third of employees in the non-financial sector are employed by SMEs, with $29.1 \%$ in micro enterprises with less than 10 persons employed and $20.2 \%$ in small enterprises with less than 49 persons employed and $17.1 \%$ in medium enterprises with less than 250 employees. All three sizes of SMEs are contributing nearly equally to value added in the EU-28 with $20.3 \%$ for micro enterprises, $17.6 \%$ for small enterprises and $18.5 \%$ for medium-sized enterprises (Eurostat 2018). Until the next SME statistics report update, planned for May 2019, recent statistics confirm that, in 2017, there were 24.6 million SMEs in the EU-28 non-financial business sector, of which $22.9(-93 \%)$ million were micro SMEs, 1.4 million were small SMEs $(-6 \%)$ and 0.2 million were medium-sized SMEs $(\sim 1 \%)$. In contrast, there were only 47,000 large enterprises (EU 2018).

The economic contribution from SMEs was particularly apparent in Malta, Cyprus, Estonia, Greece, Latvia, Lithuania, and Italy with SMEs providing more than two thirds of the total value added generated in each of their non-financial business economies. In the overall EU-28, the value-added generated by SMEs is $56.5 \%$ (Eurostat 2018).

Furthermore, the number of SMEs in the EU-28 increased by $13.8 \%$ between 2008 and 2017. SMEs represented 88.3\% of all EU-28 enterprises exporting goods. The rest of the world accounted for only $30 \%$ of all SME exports. In 2016, 80\% of all exporting SMEs were engaged in 
intra-EU trade, while less than half of exporting SMEs sold to markets outside the EU-28, and slightly more than a quarter of exporting SMEs sold to both markets (Brusselsnetwork 2018).

\subsubsection{The Role of SMEs in the United States}

In the United States, the definition of SMEs is dependent not only on the number of employees, annual sales, assets, or any combination of these, it also varies from industry to industry, based on the North American Industry Classification System (NAICS). In manufacturing, for example, an SME is defined as having 500 employees or less, whereas in wholesale trades, it is typically 100 employees or less (Madani 2018). It has to be stated here that all the following numbers refer to SMEs including also financial businesses (different to the EU definition) as the US definition makes no distinction. Small to medium enterprises also make up the vast majority of businesses in the United States. According to the U.S. Census Bureau Data from 2016, of the 5.6 million employer firms in the United States (Ward 2018):

- $99.7 \%$ had fewer than 500 employees

- $98.2 \%$ had fewer than 100 employees

- $89.0 \%$ had fewer than 20 employees.

SMEs contributed $46 \%$ of the private nonfarm GDP in 2008 (the most recent year for which the source data are available), making them hugely important for economic growth, innovation, and diversity (Ward 2018). Regarding the employed workforce, small businesses in the US employed 58.9 million people, or $47.5 \%$ of the private workforce, in 2015. SMEs contribute to economic growth in the United States as small businesses created 1.9 million net jobs in 2015. Firms employing fewer than 20 employees experienced the largest gains, adding 1.1 million net jobs. The smallest gains were in firms employing 100-499 employees, which added 387,874 net jobs (SBA 2018). 


\subsubsection{The Role of SMEs in Asia}

SMEs represent a significant proportion of enterprises, especially in developing countries, as many Asian countries are (ADB 2018). SMEs are also the backbone of the Asian economy. They make up more than 96\% of all Asian businesses, providing two out of three private-sector jobs on the continent. Therefore, it is vital for Asian economies' economic success that they have fully functioning support measures for SMEs (Yoshino and Taghizadeh-Hesary 2018).

For the 20 countries in Asia and the Pacific with available data during 2011-2014, on average, SMEs represented 62\% of national employment, ranging from 4 to $97 \%$, and accounting for $42 \%$ of gross domestic product (GDP), ranging from 12 to 60\% (ADB 2018). Also, in Asia the definition of SMEs is heterogeneous varying from country to country. For example, SMEs are defined as having up to 1000 employees in some sectors in the People's Republic of China (PRC), but the cutoff is up to 200 workers for some sectors in Thailand. Malaysia considers manufacturing firms to be SMEs if they have fewer than 200 workers or revenue of less than RM50 million (about $\$ 12$ million) (ADB 2018). In Japan, the definition of SMEs depends not only on the sector of activity but also on the value of capital and the number of employees (Madani 2018). Furthermore, very often, government agencies within the same country may use different definitions. For example, a ministry may use one definition while the national statistics office uses another, and a lending policy may adopt yet another (ADB 2018).

In the Association of Southeast Asian Nations (ASEAN) countries-Singapore, Brunei, Malaysia, Thailand, Philippines, Indonesia, Vietnam, Laos, Cambodia, Myanmar-micro, SMEs represent around $97-99 \%$ of the enterprise population. The SME sector tends to be dominated by micro enterprises, which typically account for 85-99\% of enterprises (where data are available). There is a relatively low share of medium-sized enterprises across the region as a whole, which may be indicative of a "missing middle" in the region's productive structure. In most ASEAN countries, SMEs are predominantly found in labor-intensive and low value-added sectors of the economy, particularly retail, trade, and agricultural activities. As such, they continue to account for a 
high share of employment but a low share of gross value added in most countries. In the ASEAN region, SMEs account for around $66.3 \%$ of employment (based on the median) and $42.2 \%$ of gross value added (OECD/ERIA 2018).

\subsubsection{The Role of SMEs in the World}

For statistical purposes, the following numbers refer to the European definition of SMEs as the firms employing up to 249 persons, with the following breakdown: micro (1-9), small (10-49), and medium (50-249).

According to WTO calculations based on World Bank Enterprise Surveys covering over 25,000 SMEs in developing countries, direct exports represent just $7.6 \%$ of total sales of SMEs in the manufacturing sector, compared to $14.1 \%$ for large manufacturing enterprises. Among developing regions, Africa has the lowest export share at 3\%, compared to $8.7 \%$ for developing Asia. Participation by SMEs indirect exports of services in developing countries is negligible, representing only $0.9 \%$ of total services sales compared to $31.9 \%$ for large enterprises (WTO 2016).

In many countries, and in particular Organization for Economic Cooperation and Development (OECD) countries, SMEs are key players in the economy and the wider eco-systems of firms. In the OECD area, SMEs are the predominant form of enterprise, accounting for approximately $99 \%$ of all firms. They provide the main source of employment, accounting for about $70 \%$ of jobs on average, and are major contributors to value creation, generating between 50 and $60 \%$ of value added on average. In emerging economies, SMEs contribute up to $45 \%$ of total employment and $33 \%$ of GDP. When taking the contribution of informal businesses into account, SMEs contribute to more than half of employment and GDP in most countries irrespective of income levels. In addition, SME development can contribute to economic diversification and resilience and therefore to a more sustainable economy. This is especially relevant for resource-rich countries that are particularly vulnerable to commodity price fluctuations (OECD 2017). 


\subsection{Current State of the Transition of Industry 4.0 to SMEs}

\subsubsection{State of the Art of Industry 4.0 for SMEs in Scientific Literature}

For an analysis of the state of the art in the field of Industry 4.0 for SMEs, the scientific literature with the keywords "Industry 4.0" as well as "Smart Manufacturing" in the title, keywords and abstract is linked with the occurrence of the keywords "small- and medium-sized enterprises" as well as "SME" in the title of the papers. For the analysis, the database Scopus is used, which is known as a high-quality and comprehensive scientific database in the field of engineering. The results of the search are a list of 55 papers, of which 25 are conference contributions, 23 are journal articles, 5 book chapters, and 2 are reviews. The search results show an important increase in scientific papers starting from 2017 (see Table 1.1). Also, the found literature at the date of the search leads to the hypothesis that the topic Industry 4.0 in SMEs is of increasing importance for scholars in engineering and production research.

In the following, we will summarize the main findings in the current state analysis based on the identified papers. At the beginning of the scientific discussions of "Industry 4.0", most of the papers describe the big challenge that SMEs will face with the new hype of Industry 4.0 (Färber 2013; Matt et al. 2016). Later Reuter (2015) addresses the future importance of Industry 4.0 and IT in business continuity management of SMEs, but remains very vague about the use of the term

Table 1.1 Search results in SCOPUS

\begin{tabular}{ll}
\hline Year & Papers \\
\hline $2019^{a}$ & 9 \\
2018 & 27 \\
2017 & 12 \\
2016 & 5 \\
2015 & 1 \\
2013 & 1 \\
Sum & 55 \\
\hline
\end{tabular}

a28 March 2019 
"Industry 4.0". Decker (2017) analyzes the readiness of Danish SMEs from the metal processing sector for Industry 4.0 using case study research. Up to this point, there was no maturity or readiness model available and thus the analysis was conducted basically on a qualitative level. The basic outcome is that SMEs at this time were not sure if, when and how they should start to introduce Industry 4.0 in their firms. Bollhöfer et al. (2016) describe the potential of service-based business models for SMEs although many uncertainties and barriers (see also Müller and Voigt 2016) discourage or limit SMEs from starting an implementation process for Industry 4.0. Later Seidenstricker et al. (2017), Safar et al. (2018), Müller (2019), and Bolesnikov et al. (2019) describe specific frameworks for introducing new and innovative as well as digital business models in SMEs. In 2016, Ganzarain and Errasti (2016) are the first to discuss the adoption of maturity models in SMEs to support the implementation of Industry 4.0 in SMEs. Later also, other authors like Wiesner et al. (2018) and Jones et al. (2018) came up with SME-specific maturity and readiness models. Mittal et al. (2018a) reviewed different smart manufacturing and Industry 4.0 maturity models and their implications for SMEs. Matt et al. (2016) describe a very early first attempt at a methodical approach to how SMEs can introduce Industry 4.0. Later in 2018, they refine the approach to a five-step methodology for SMEs (Matt et al. 2018a). Jørsfeldt and Decker (2017) as well as Jun et al. (2017) promote the concept of digitally enabled platforms generating entrepreneurial opportunities for smart SMEs but up to now such platforms do not really exist. Bakkari and Khatory (2017) as well as Schlegel et al. (2017) encourage SMEs in their works to put a certain emphasis on Industry 4.0 strategies in the integration of concepts for a more sustainable and ecological manufacturing environment. At this time, the concepts proposed are still on a very rough and abstract level without any clear and tangible recommendations about how to achieve the proposed goals. Several works try also to combine the advantages of Lean and Industry 4.0 or discuss why both principles are complementary and do not exclude each other (Matt et al. 2016; Müller et al. 2017; Rauch et al. 2017). Other papers are presenting competence centers, learning factories, and laboratories for Industry 4.0 specific research, training offers or knowledge transfer 
to smaller firms (Müller and Hopf 2017; Scheidel et al. 2018; Gualtieri et al. 2018). Rauch et al. (2018b) used Axiomatic Design in their research to develop a methodology for SMEs in order to introduce flexible and agile manufacturing systems. Goerzig and Bauernhansl (2018) propose a framework architecture for SMEs adopting Industry 4.0 in their firm. Similarly, other researchers are working on the development of Industry 4.0 tool kits and roadmaps in order to simplify the introduction of Industry 4.0 in SMEs (Mittal et al. 2018b; Modrak et al. 2019). Further investigation has also been started on social sustainability in SME manufacturing in the context of Industry 4.0 (Matt et al. 2018b). Moica et al. (2018) address the need of Industry 4.0 also for shop floor management and Menezes et al. (2017) the need for adapted Manufacturing Execution Systems (MES) for SMEs. Other works discuss the need for retrofitting old machinery to be prepared for Industry 4.0 (Pérez et al. 2018). Although the discussion about artificial intelligence had already started, Sezer et al. (2018) address the technologies to be used for low-cost predictive maintenance in SMEs. As Industry 4.0 is not limited to SMEs working in the manufacturing sector, Nowotarski and Paslawski (2017) started also to investigate the use of Industry 4.0 methods and technologies on-site in the construction industry, Weiß et al. (2018) in the textile industry and Zambon et al. (2019) in agriculture.

Analyzing the content of the identified scientific papers about Industry 4.0 in SMEs, the following hypotheses can be derived:

- Several works are dealing with innovative and digital business models, also putting SMEs in a position to take advantage of Industry 4.0 as a business model.

- Researchers propose that digital platforms are interesting opportunities for SMEs to increase their business, but there are no relevant implementations of such SME platforms up to now.

- Several researchers are working on readiness, assessment, or maturity models to help SMEs understand their actual status.

- There is a rising number of works on frameworks, tool sets as well as roadmaps to guide SMEs in the implementation of Industry 4.0. 
- It seems that Industry 4.0 is more and more of interest for other industries rather than manufacturing (construction, textile, agriculture).

- Although there is still little research about artificial intelligence in manufacturing in general, there are first attempts to introduce low cost and easy approaches also in SMEs.

- Sustainability (in the sense of ecological as well as social sustainability) is gaining attention.

\subsubsection{Current EU Research Initiatives on Industry 4.0 for SMEs}

As identified in the current state of research and scientific literature, there is still need to further investigate the transition to Industry 4.0 in SME firms. The European Commission is already financing a few projects related to this important niche topic. A first small H2020 research project with around $€ 70,000$ of project volume with the title "Industrial FW 4.0 - Internet 4.0 based MES for the SME sector" (Grant agreement ID: 710130) was awarded in 2015 and ended in 2016. The first important research initiative in this direction started in January 2017 with the project "SME 4.0 - Industry 4.0 for SMEs" (Grant agreement ID: 734713) funded by the EC H2020 program. The details regarding this project will be explained in the following Sect. 1.5. In April 2017, the H2020 project "IoT4Industry - Towards smarter means of production in European manufacturing SMEs through the use of the Internet of Things technologies" (Grant Agreement 777455) started. Later, in October 2017, the H2020 project "L4MS - Logistics for Manufacturing SMEs" (Grant Agreement 767642) was awarded with funding of nearly $€ 8$ mio to investigate IoT platforms and smartization services for logistics in SMEs from manufacturing. Another related project is "ENIT - Agent 2.0 - The world's first edge computing solution for SMEs enabling energy efficiency, Industry 4.0 and new business models for the energy sector" (Grant agreement ID: 811640) with a project volume of $€ 2$ mio and EU funding of $€ 1.4$ mio which started in 2018 and focuses on the adoption of Industry 4.0 technologies in SMEs 
for energy management. A recently started small scale (project volume of around $€ 70,000) \mathrm{H} 2020$ project is "Katana - Bringing Industry 4.0 to the hands of small manufacturers: Feasibility study for scaling up Katana smart workshop software" (Grant agreement ID: 855987) which aims to realize smart workshop software for SMEs (Cordis 2019).

\subsubsection{Summary of the State-of-the-Art Analysis}

Both in the analysis of scientific works and of EU projects to research the introduction of Industry 4.0 in SMEs, it can be seen that the topic is still relatively "young" and unexplored as it has basically only been dealt with seriously since 2017. Therefore, it will require further efforts to provide appropriate instruments for SMEs introducing Industry 4.0 in practice. What is striking is that there are no best practice examples of SMEs where a big part of the Industry 4.0 technologies have been successfully adopted. For this reason, more attention should be paid to this in future work and pilot introductions in SMEs should be accompanied and documented by scientists. In addition, the overview of current research initiatives in Europe showed that the "SME 4.0" project is currently the only initiative that considers the problem holistically and from an international point of view and is not limited to partial aspects of Industry 4.0 in SMEs.

\subsection{SME 4.0—Industry 4.0 for SMEs}

\subsection{1 "SME 4.0" Project Key Data and Objectives}

The research project "SME 4.0" with the full title "Industry 4.0 for SMEs-Smart Manufacturing and Logistics for SMEs in an X-toorder and Mass Customization Environment" and a project volume of $€ 954,000$ received $€ 783,000$ funding from the European Commission H2020 MSCA Research and Innovation Staff Exchange (RISE) program. The project has a duration of four years starting in 2017 and ending at the end of 2020. The project consortium consists of the following 


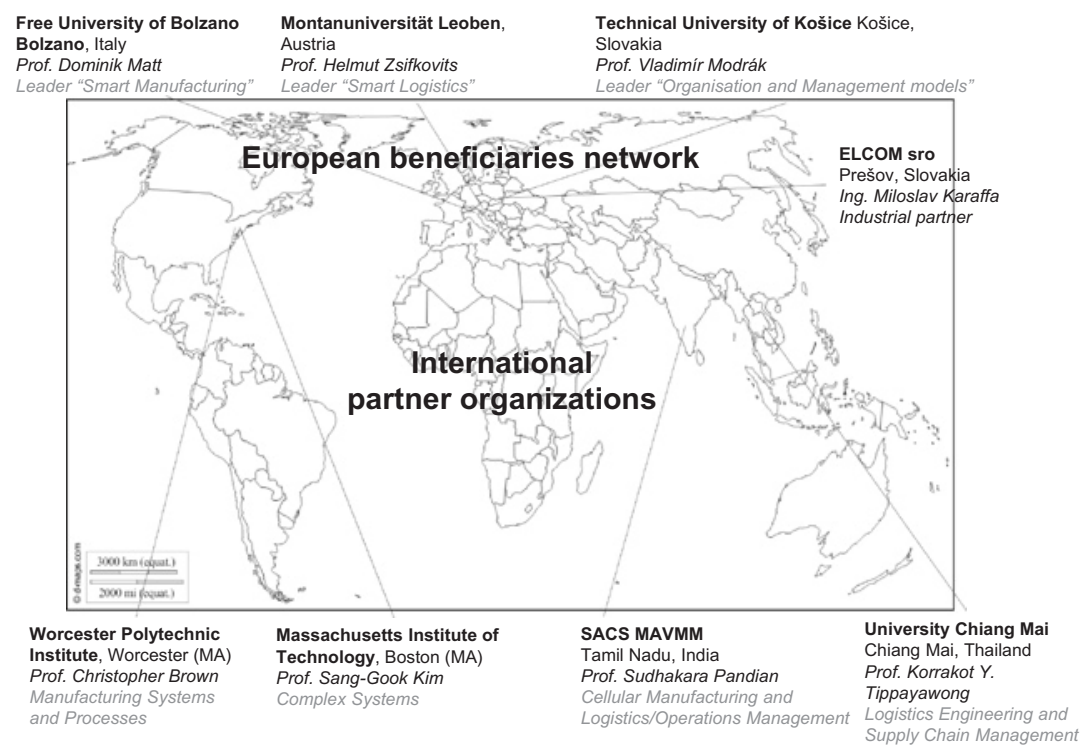

Fig. 1.2 European beneficiaries and international partner organizations in the project (Source of the map www.d-maps.com)

four European beneficiaries, both from academia and industry, as well as four academic partner organizations from the USA, Thailand, and India (see also Fig. 1.2):

- Free University of Bolzano-Bozen, Italy (project coordinator and EU beneficiary)

- Technical University of Kosice, Slovakia (EU beneficiary)

- Montanuniversität Leoben, Austria (EU beneficiary)

- Elcom sro Presov, Slovakia (EU beneficiary)

- MIT Massachusetts Institute of Technology, USA (partner organization)

- WPI Worcester Polytechnic Institute, USA (partner organization)

- Chiang Mai University, Thailand (partner organization)

- SACS MAVMM Engineering College, India (partner organization). 
As the first large research initiative in Europe to investigate the introduction of Industry 4.0 in SMEs, the project covers the following specific research questions:

A. Identification of requirements for Industry 4.0 applications and implementation in SME manufacturing and logistics:

- What are the actual known concepts and technologies of Industry 4.0 ?

- What are the main opportunities/risks for the use of these concepts in SMEs?

- How suitable are the different concepts for application in SMEs?

- What are SME-specific requirements for the adaptation of the most promising concepts and technologies?

B. Development of SME-specific concepts and strategies for smart and intelligent SME manufacturing and logistics:

- What are possible forms or migration levels for realizing smart and intelligent manufacturing systems for $\mathrm{x}$-to-order and mass customization production?

- How can automation, advanced manufacturing technologies, ICT, and CPS improve productivity in SME manufacturing and logistics?

- What are suitable models for smart and lean supply chains in SME logistics?

C. Development of specific organization and management models for smart SMEs:

- What are innovative and promising new business models for smart SMEs?

- What are optimal implementation strategies for the introduction of Industry 4.0 in SMEs?

- What are ideal organizational models for smart SMEs or SME networks? 
In addition to the above described research questions, the project aims to achieve the following general objectives in relation to the European Community:

- Ensure the transfer of Industry 4.0 to SMEs through adapted template models;

- Maintain and develop the competitive level of European SMEs;

- Accelerate the transition of Industry 4.0 from research to practice;

- Maintain the prosperity of the European population by securing jobs;

- Develop and progress the careers of European experts and qualified young scientists in SME research for Industry 4.0.

\subsubsection{Project Structure}

The project is organized into three research fields (RF) (Fig. 1.3): (i) smart manufacturing in SMEs, specific solutions for (ii) smart logistics in SMEs and (iii) adapted organization and management models for the introduction of Industry 4.0 and the management of smart SMEs. These research fields are further decomposed into nine research topics (RT) to investigate specific concepts.
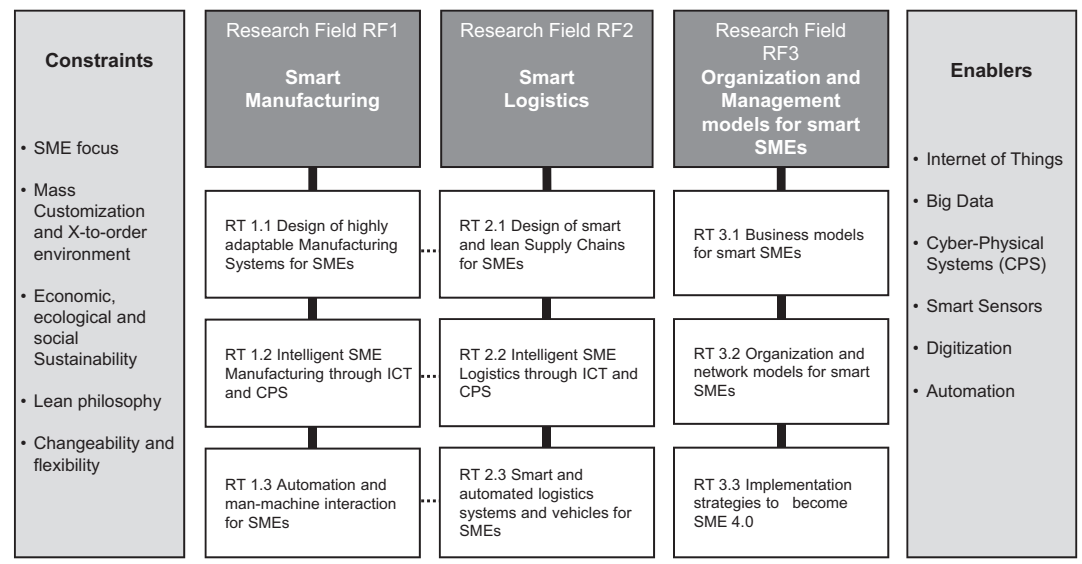

Fig. 1.3 Research fields and topics in the SME 4.0 project 
The research project, with a duration of four years, is divided into two equal phases each of two years (see Fig. 1.4).

The first phase from 2017 to 2018 was dedicated to analyzing existing Industry 4.0 concepts and to investigating their suitability for SMEs and/or their need to be adapted for the specific requirements of SMEs. Therefore, the first phase was used also to collect and analyze the requirements of SMEs to introduce Industry 4.0 in small- and medium-sized firms. In the first operative work package (WP3), the research team analyzed the Industry 4.0 requirements in manufacturing with a special focus on the need for adaptable manufacturing systems, the potential of ICT and CPS in manufacturing and the potential of automation in small and medium firms. In WP4, a similar approach is used to investigate the requirements and opportunities of Industry 4.0 in SME logistics. In WP5, the research team analyzed the suitability of SMEs strategies for the introduction of Industry 4.0; they collected organizational requirements for smart SMEs and analyzed the current state of methods and tools for the implementation of Industry 4.0 in SMEs. The content of this book is directly related to this first project phase and summarizes the scientific findings and results.

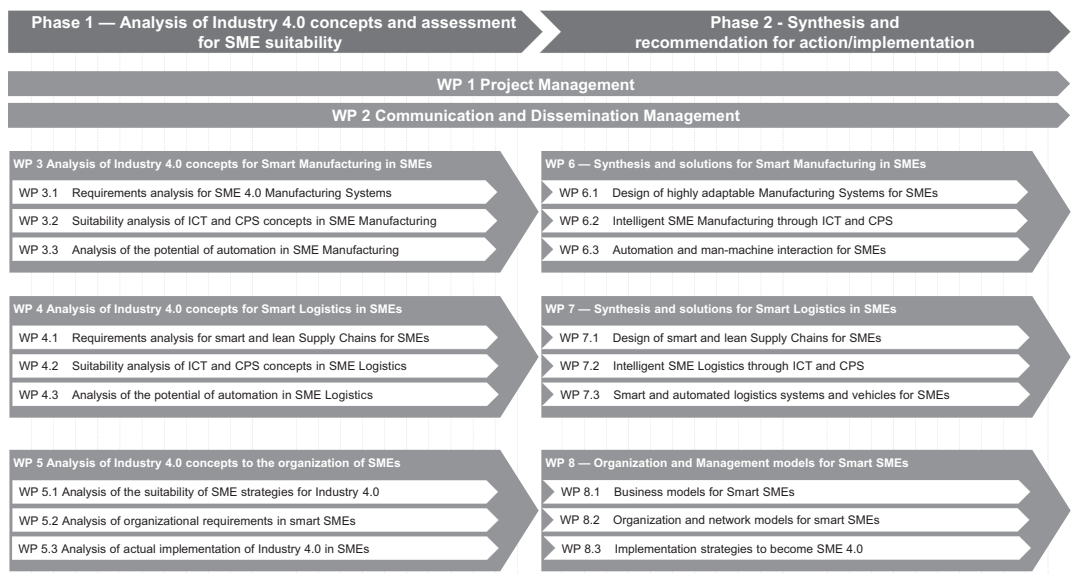

Fig. 1.4 Work packages, tasks, and project phases 
The second phase from 2019 to 2020 is dedicated to the synthesis of the results of the first phase and the elaboration of methods, tools, and recommendations for actions to support SMEs introducing Industry 4.0. Similarly to the first phase, we have three work packages (WP) for the derivation of measures for manufacturing, logistics, and organizational issues. The main expected results of the WP6 are to design guidelines and templates for highly adaptable SME manufacturing systems, ICT and CPS-based solutions for more intelligent manufacturing as well as enabling easy implementation of solutions for automation in collaboration with the human on the shop floor. In WP7, related to logistics, the main expected results are templates and guidelines for smart and lean supply chains, the use of ICT and CPS for a smarter supply chain as well as easy and low-cost solutions for automation in intralogistics and transport. In WP8, the expected results are the elaboration of a generally applicable business model (or business models) for smart SMEs, smarter processes and organizational models as well as Industry 4.0 implementation strategies, roadmaps and supporting assessment models for SMEs. The findings of this second project phase will be summarized in a second book project planned to be published by the end of the project.

\subsubsection{Research Methodology in the First Project Phase}

In the first project phase, the research team adopted a dual strategy using primary research methods (direct collection of data and information from SMEs) as well as secondary research methods (analysis of data collected/published from previously undertaken research or other sources). This kind of research strategy was chosen, as in the scientific literature (especially before 2017) only a few works dealt with Industry 4.0 and the specific needs of SMEs.

In order to analyze the current state of the art as well as the existing Industry 4.0 technologies and concepts, secondary research was used by using literature research methods like the Systematic Literature Review (SLR) (Booth et al. 2016). For secondary research, the research team used explorative field studies with focus groups (Becker et al. 2009; 
Wölfel et al. 2012) organizing four SME workshops in 2017. In each of the four workshops held in Italy, Austria, USA, and Thailand, a number of around 10 SMEs participated (total number of 37 SMEs in the workshop series). The workshops had a standardized structure in order to guarantee comparable results. Based on the results of the literature search and the SME workshops, the research consortium worked on the results of this first project phase.

In addition, the research team also visited different SMEs to get a practical understanding of the problems and requirements of SMEs. Through the industry partner Elcom sro, the voice of SMEs is also represented in the research consortium to monitor that research is characterized by a practical approach.

\subsection{Conclusion and Structure of the Book}

This chapter has shown how important SMEs are in Europe as well as in all other economies of the world. Industry 4.0 is also a major challenge for large enterprises, which in turn, have the necessary financial and human resources to introduce industry into their enterprises. For SMEs, it is not a question of whether they should introduce Industry 4.0 or not, but rather how they can do so as quickly as possible in order to maintain or achieve a large competitive advantage. As the analysis of the research has shown, the research on Industry 4.0 for SMEs is still in its infancy.

This book represents a first major step in this direction by analyzing and describing the challenges, opportunities, and requirements of SMEs in terms of manufacturing, logistics, and organization. Therefore, this book is organized into several sections, which summarize the results of the research according to the topic. The second section focuses on Industry 4.0 concepts for smart manufacturing in SMEs. In addition to the detailed analysis of the requirements for a highly adaptable manufacturing system, it also describes how an Industrial IoT and CPS can be implemented and what kind of potential and challenges SMEs expect to face when they start to implement manufacturing automation and human-robot collaboration. In the third section, the focus is 
on Industry 4.0 concepts for smart logistics in SMEs. Here the authors provide detailed information about the requirements for designing smart supply chains, they analyze the use of ICT and embedded systems for tracking and tracing in SME logistics and they review the state of the art of automation in logistics. In the fourth section, the work is focused on the organization of smart SMEs. Innovative organizational models for mass customization are developed and tested and the major limitations and barriers to SMEs introducing Industry 4.0 are studied. Finally, a toolkit for the implementation of Industry 4.0 is proposed in order to support SMEs in this challenging initial phase. The fifth section is dedicated to practical case studies on how Industry 4.0 has been applied in a laboratory environment or in real industrial situations. This section is a valuable addition to the previously discussed chapters on smart manufacturing, smart logistics, and organization in smart SMEs. In the case studies, the authors describe both the underlying theoretical concepts and their practical implementation and validation. Readers can expect practical insights into automatic product identification and inspection by means of Industry 4.0 as well as into intuitive collaboration between man and machine in SME assembly. The last chapter of this book explains the basics of Axiomatic Design. As several of the chapters use Axiomatic Design as a research method, the chapter is intended to present the necessary basics and to make it possible to refer to these basics in the individual chapters.

\section{References}

Acatech. 2013. Bundeskanzlerin Angela Merkel nimmt Bericht des Arbeitskreises Industrie 4.0 entgegen. https://www.acatech.de/allgemein/bundeskanzlerin-angela-merkel-nimmt-bericht-desarbeitskreises-industrie-4-0-entgegen/. Accessed on 23 Mar 2019.

ADB. 2018. Support for Small and Medium-Sized Enterprises, 2005-2017: Business Environment, Access to Finance, Value Chains, and Women in Business, Linked Document, A Small and Medium-Sized Enterprises in Asia and the Pacific: Context and Issues. https://www.adb.org/sites/default/ files/linked-documents/A-SME-Context-and-Issues.pdf. Accessed on 21 Feb 2019. 
Bakkari, M., and A. Khatory. 2017. Industry 4.0: Strategy for More Sustainable Industrial Development in SMEs. In Proceedings of the IEOM 7th International Conference on Industrial Engineering and Operations Management, 11-13. Rabat, Morocco. https://pdfs.semanticscholar.org/ca4b/ 140f92a0bbbeee7dd0604f5ea33c77636ad4.pdf. Accessed on Aug 2019.

Balkhausen, D. 1978. Die dritte industrielle Revolution, wie die Mikroelektronik unser Leben verändert. Düsseldorf und Wien: Econ Verlag.

Bär, K., Z.N.L. Herbert-Hansen, and W. Khalid. 2018. Considering Industry 4.0 Aspects in the Supply Chain for an SME. Production Engineering 12 (6): 747-758. https://doi.org/10.1007/s11740-018-0851-y.

Bauer, W., S. Schlund, D. Marrenbach, and O. Ganschar. 2014. Industrie 4.0 - Volkswirtschaftliches Potenzial für Deutschland. BITKOM, 18. Berlin: Das Fraunhofer-Institut für Arbeitswirtschaft und Organisation. https:// doi.org/10.1007/978-3-642-36917-9.

Baum, G. 2013. Innovationen als Basis der nächsten Industrierevolution. In Industrie 4.0, ed. U. Sendler, 37-53. Berlin and Heidelberg: Springer Vieweg. https://doi.org/10.1007/978-3-642-36917-9_3.

Becker, J., D. Beverungen, M. Matzner, and O. Müller. 2009. Design Requirements to Support Information Flows for Providing Customer Solutions: A Case Study in the Mechanical Engineering Sector. In Proceedings of the First International Symposium on Services Science, Leipzig, Germany.

BMBF. 2012. Zukunftsbild Industrie 4.0. https://www.plattform-i40.de/PI40/

Redaktion/DE/Downloads/Publikation/zukunftsbild-industrie-4-0.pdf?

blob=publicationFile\&v=4. Accessed on 23 Mar 2019.

Bolesnikov, M., M. Popović Stijačić, M. Radišić, A. Takači, J. Borocki, D. Bolesnikov, and J. Dzieńdziora. 2019. Development of a Business Model by Introducing Sustainable and Tailor-Made Value Proposition for SME Clients. Sustainability 11 (4): 1157. https://doi.org/10.3390/su11041157.

Bollhöfer, E., D. Buschak, and C. Moll. 2016. Dienstleistungsbasierte Geschäftsmodelle für Industrie 4.0-aktueller Stand und Potenziale für KMU. In Multikonferenz Wirtschaftsinformatik, 1287-1298. Ilmenau: Universitätsverlag Ilmenau.

Booth, A., A. Sutton, and D. Papaioannou. 2016. Systematic Approaches to a Successful Literature Review, 2nd ed. London: Sage.

Boughton, N.J., and I.C. Arokiam. 2000. The Application of Cellular Manufacturing: A Regional Small to Medium Enterprise Perspective. Proceedings of the Institution of Mechanical Engineers, Part B: Journal of Engineering Manufacture 214 (8): 751-754. https://doi. org/10.1243/0954405001518125. 
Brettel, M., N. Friederichsen, M. Keller, and M. Rosenberg. 2014. How Virtualization, Decentralization and Network Building Change the Manufacturing Landscape: An Industry 4.0 Perspective. International Journal of Mechanical, Industrial Science and Engineering 8 (1): 37-44. https://doi.org/10.5281/zenodo.1336426.

Brusselsnetwork. 2018. Annual Report 2018 on European SMEs. https:// www.brusselsnetwork.be/annual-report-2018-on-european-smes/. Accessed on 27 Dec 2018.

Cordis. 2019. Cordis EU Research Results. https://cordis.europa.eu. Accessed on 27 Mar 2019.

Decker, A. 2017. Industry 4.0 and SMEs in the Northern Jutland Region. In Value Creation in International Business, 309-335. Cham: Palgrave Macmillan. http://dx.doi.org/10.1007/978-3-319-39369-8_13.

Deloitte. 2015. Industry 4.0-Challenges and Solutions for the Digital Transformation and Use of Exponential Technologies. Study of Deloitte Consulting. http://www2.deloitte.com/content/dam/Deloitte/ch/ Documents/manufacturing/ch-en-manufacturing-industry-4-0-24102014. pdf. Accessed on 7 Jan 2016.

EC. 2015. Industry 4.0-Digitalisation for Productivity and Growth. http:// www.europarl.europa.eu/RegData/etudes/BRIE/2015/568337/EPRS_ BRI(2015)568337_EN.pdf. Accessed on 27 Mar 2019.

EC. 2018. Commission Proposal for the Next Research and Innovation Programme (2021-2027). Horizon Europe. https://ec.europa.eu/info/sites/ info/files/horizon-europe-presentation_2018_en.pdf. Accessed on 27 Mar 2019.

EU. 2018. Small and Medium-Sized Enterprises: An Overview. Annual Report on European SMEs 2017/2018. Special Background Document on the Internationalisation of SMEs. SME Performance Review 2017/2018. eurostat. https://ec.europa.eu/eurostat/web/products-eurostat-news/-/EDN20181119-1. Accessed on 3 Dec 2019.

Eurostat. 2018. Statistics on Small and Medium-Sized Enterprises. https:// ec.europa.eu/eurostat/statistics-explained/index.php?title=Statistics_on_ small_and_medium-sized_enterprises\&oldid $=451334$. Accessed on 29 Sept 2019.

Färber, R. 2013. Hype trifft Mittelstand: Relevanz von Industrie 4.0 für kleine und mittelständische Unternehmen. Mechatronik 121 (12): 45-47.

FAZ. 2019. https://www.faz.net/aktuell/wirtschaft/infografik-made-in-china2025-15936600.html. Accessed on 27 Mar 2019. 
Ganzarain, J., and N. Errasti. 2016. Three Stage Maturity Model in SME's Toward Industry 4.0. Journal of Industrial Engineering and Management 9 (5): 1119-1128. https://doi.org/10.3926/jiem.2073.

Goerzig, D., and T. Bauernhansl. 2018. Enterprise Architectures for the

Digital Transformation in Small and Medium-Sized Enterprises. Procedia CIRP 67 (1): 540-545. https://doi.org/10.1016/j.procir.2017.12.257.

Gualtieri, L., R. Rojas, G. Carabin, I. Palomba, E. Rauch, R. Vidoni, and D.T. Matt. 2018. Advanced Automation for SMEs in the I4. 0 Revolution: Engineering Education and Employees Training in the Smart Mini Factory Laboratory. In 2018 IEEE International Conference on Industrial Engineering and Engineering Management (IEEM), 1111-1115. https://doi. org/10.1109/IEEM.2018.8607719.

Hartbrich, I. 2014. Industrie 4.0-in der Zukunftsfabrik. Die Zeit 5 (1): 1-3. Jones, M., L. Zarzycki, and G. Murray. 2018. Does Industry 4.0 Pose a Challenge for the SME Machine Builder? A Case Study and Reflection of Readiness for a UK SME. In International Precision Assembly Seminar, 183197. Cham: Springer. https://doi.org/10.1007/978-3-030-05931-6_17. Jørsfeldt, L.M., and A. Decker. 2017. Digitally Enabled Platforms: Generating Innovation and Entrepreneurial Opportunities for SMEs. In Motivating SMEs to Cooperate and Internationalize, 93-111. Routledge. https://doi. org/10.4324/9781315412610.

Jun, C., J.Y. Lee, J.S. Yoon, and B.H. Kim. 2017. Applications' Integration and Operation Platform to Support Smart Manufacturing by Small and Medium-Sized Enterprises. Procedia Manufacturing 11: 1950-1957. https:// doi.org/10.1016/j.promfg.2017.07.341.

Kagermann, H., J. Helbig, A. Hellinger, and W. Wahlster. 2013. Recommendations for Implementing the Strategic Initiative Industrie 4.0: Securing the Future of German Manufacturing Industry. Final report of the Industrie 4.0 Working Group. Forschungsunion.

Laperrire, L., and G. Reinhart. 2014. CIRP Encyclopedia of Production Engineering. Springer. http://dx.doi.org/10.1007/978-3-642-20617-7.

Lee, J., B. Bagheri, and H.A. Kao. 2015. A Cyber-Physical Systems Architecture for Industry 4.0-Based Manufacturing Systems. Manufacturing Letters 3: 18-23. https://doi.org/10.1016/j.mfglet.2014.12.001.

Lee, J., and E. Lapira. 2013. Predictive Factories: The Next Transformation. Manufacturing Leadership Journal 20 (1): 13-24. https://doi. org/10.3182/20130522-3-BR-4036.00107. 
Lee, E.A., and S.A. Seshia. 2016. Introduction to Embedded Systems: A CyberPhysical Systems Approach. Cambridge: MIT Press.

Madani, A.E. 2018. SME Securitization in SME Policy: Comparative Analysis of SME Definitions. International Journal of Academic Research in Business and Social Sciences 8 (8): 103-114. https://doi.org/10.6007/IJARBSS/ v8-i8/4443.

Manhart, K. 2013. Industrie 4.0 könnte schon bald Realität sein. https:// computerwelt.at/knowhow/industrie-4-0-konnte-schon-bald-realitat-sein/. Accessed on 15 Mar 2015.

Manufacturing USA. 2019. https://www.manufacturingusa.com/. Accessed on 25 Mar 2019.

Matt, D.T. 2007. Reducing the Structural Complexity of Growing Organizational Systems by Means of Axiomatic Designed Networks of Core Competence Cells. Journal of Manufacturing Systems 26 (3-4): 178-187. https://doi.org/10.1016/j.jmsy.2008.02.001.

Matt, D.T., E. Rauch, and D. Fraccaroli. 2016. Smart Factory for SMEs: Designing a Holistic Production System by Industry 4.0 Vision in Small and Medium Enterprises (SMEs). ZWF Zeitschrift für wirtschaftlichen Fabrikbetrieb 111: 2-5. https://doi.org/10.3139/104.111471.

Matt, D.T., E. Rauch, and M. Riedl. 2018a. Analyzing the Impacts of Industry 4.0 in Modern Business Environments. Knowledge Transfer and Introduction of Industry 4.0 in SMEs: A Five-Step Methodology to Introduce Industry 4.0, 256-282. IGI Global. https://doi. org/10.4018/978-1-5225-3468-6.

Matt, D.T., G. Orzes, E. Rauch, and P. Dallasega. 2018b. Urban Production-A Socially Sustainable Factory Concept to Overcome Shortcomings of Qualified Workers in Smart SMEs. Computers \& Industrial Engineering. https://doi.org/10.1016/j.cie.2018.08.035.

Meissner, H., R. Ilsen, and J.C. Aurich. 2017. Analysis of Control Architectures in the Context of Industry 4.0. Procedia CIRP 62: 165-169. https://doi.org/10.1016/j.procir.2016.06.113.

Menezes, S., S. Creado, and R.Y. Zhong. 2017. Smart Manufacturing Execution Systems for Small and Medium-Sized Enterprises. Decision Making 13: 14. https://doi.org/10.1016/j.procir.2018.03.272.

Mittal, S., M.A. Khan, D. Romero, and T. Wuest. 2018a. A Critical Review of Smart Manufacturing \& Industry 4.0 Maturity Models: Implications for Small and Medium-Sized Enterprises (SMEs). Journal of Manufacturing Systems 49: 194-214. https://doi.org/10.1016/j.jmsy.2018.10.005. 
Mittal, S., D. Romero, and T. Wuest. 2018b. Towards a Smart Manufacturing Toolkit for SMEs. In IFIP International Conference on Product Lifecycle Management, 476-487. Cham: Springer. https://doi. org/10.1007/978-3-030-01614-2_44.

Modrak, V., D. Marton, and S. Bednar. 2014. Modeling and Determining Product Variety for Mass-Customized Manufacturing. Procedia CIRP 23: 258-263. https://doi.org/10.1016/j.procir.2014.10.090.

Modrak, V., Z. Soltysova, and R. Poklemba. 2019. Mapping Requirements and Roadmap Definition for Introducing I 4.0 in SME Environment. In Advances in Manufacturing Engineering and Materials, 183-194. Cham: Springer. http://dx.doi.org/10.1007/978-3-319-99353-9_20.

Moica, S., J. Ganzarain, D. Ibarra, and P. Ferencz. 2018. Change Made in Shop Floor Management to Transform a Conventional Production System into an "Industry 4.0": Case Studies in SME Automotive Production Manufacturing. In 2018 7th International Conference on Industrial Technology and Management (ICITM), 51-56. https://doi.org/10.1109/ icitm.2018.8333919.

Monostori, L. 2014. Cyber-Physical Production Systems: Roots, Expectations and R\&D Challenges. Procedia CIRP 17: 9-13. https://doi.org/10.1016/j. procir.2014.03.115.

Moreira, C.F. 2017. The Make in India Initiative and the Role of Industry 4.0. https://www.enterprisetv.com.my/the-make-in-india-initiative-and-the-roleof-industry-4-0/. Accessed on 22 Mar 2019.

Müller, J.M. 2019. Business Model Innovation in Small- and Medium-Sized Enterprises: Strategies for Industry 4.0 Providers and Users. Journal of Manufacturing Technology Management, in press. https:/doi.org/10.1108/ JMTM-01-2018-0008.

Müller, E., and H. Hopf. 2017. Competence Center for the Digital Transformation in Small and Medium-Sized Enterprises. Procedia Manufacturing 11: 1495-1500. https://doi.org/10.1016/j.promfg.2017.07.281. Müller, J., and K.I. Voigt. 2016. Industrie 4.0 für kleine und mittlere Unternehmen. Welche spezifischen Probleme werden bei der Einführung von Industrie 4.0 von kleinen und mittleren Unternehmen gesehen? Productivity Management 3: 28-30.

Müller, R., M. Vette, L. Hörauf, C. Speicher, and D. Burkhard. 2017. Lean Information and Communication Tool to Connect Shop and Top Floor in Small and Medium-Sized Enterprises. Procedia Manufacturing 11: 10431052. https://doi.org/10.1016/j.promfg.2017.07.215. 
NSF. 2019. https://www.nsf.gov/div/index.jsp?div=CMMI. Accessed on 24 Mar 2019.

Nowotarski, P., and J. Paslawski. 2017. Industry 4.0 Concept Introduction into Construction SMEs. IOP Conference Series: Materials Science and Engineering 245 (5), 52043. http://dx.doi. org/10.1088/1757-899X/245/5/052043.

OECD. 2017. Enhancing the Contributions of SMEs in a Global and Digitalized Economy. https://www.oecd.org/mcm/documents/C-MIN2017-8-EN.pdf. Accessed on 20 Mar 2019.

OECD/ERIA. 2018. SME Policy Index: ASEAN 2018: Boosting Competitiveness and Inclusive Growth. Paris/Economic Research Institute for ASEAN and East Asia, Jakarta: OECD Publishing. https://doi.org/10.1787/978926430 5328-en.

Olle, W., \& D. Clauß. (2015). Industrie 4.0 braucht den MittelstandKurzstudie. Chemnitz Automotive Institute. http://cati.institute/wp-content/uploads/2015/03/Kurzstudie_Endfassung.pdf. Accessed on 15 Aug 2019.

Orzes, G., E. Rauch, S. Bednar, and R. Poklemba. 2018. Industry 4.0 Implementation Barriers in Small and Medium Sized Enterprises: A Focus Group Study. In 2018 IEEE International Conference on Industrial Engineering and Engineering Management (IEEM), 1348-1352. https://doi. org/10.1109/IEEM.2018.8607477.

Pérez, J.D.C., R.E.C. Buitrón, and J.I.G. Melo. 2018. Methodology for the Retrofitting of Manufacturing Resources for Migration of SME Towards Industry 4.0. In International Conference on Applied Informatics, 337-351. Cham: Springer. https://doi.org/10.1007/978-3-030-01535-0_25.

Plattform Industrie 4.0. 2014. Plattform Industrie 4.0. http://www.plattform-i40.de/. Accessed on 2 Nov 2014.

Plattform Industrie 4.0. 2019. Industrie 4.0-A Competitive Edge for Europe. https://www.plattform-i40.de/I40/Navigation/EN/InPractice/International/ EuropaeischeEbene/europaeische-ebene.html. Accessed on 26 Mar 2019.

PWC. 2015. Industry 4.0-Opportunities and Challenges of the Industrial Internet. Study of Pricewaterhouse Coopers PWC. http://www.strategyand. pwc.com/media/file/Industry-4-0.pdf. Accessed on 22 Dec 2015.

Rajkumar, R., I. Lee, L. Sha, and J. Stankovic. 2010. Cyber-Physical Systems: the Next Computing Revolution. In Design Automation IEEE International Conference on Industrial Engineering and Engineering Management, 731736. https://doi.org/10.1145/1837274.1837461. 
Rauch, E., P. Dallasega, and D.T. Matt. 2017. Critical Factors for Introducing Lean Product Development to Small and Medium Sized Enterprises in Italy. Procedia CIRP 60: 362-367. https://doi.org/10.1016/j.procir.2017.01.031. Rauch, E., P. Dallasega, and D.T. Matt. 2018a. Complexity Reduction in Engineer-to-Order Industry Through Real-Time Capable Production Planning and Control. Production Engineering 12 (3-4): 341-352. https:// doi.org/10.1007/s11740-018-0809-0.

Rauch, E., P.R. Spena, and D.T. Matt. 2018b. Axiomatic Design Guidelines for the Design of Flexible and Agile Manufacturing and Assembly Systems for SMEs. International Journal on Interactive Design and Manufacturing (IJIDeM), 1-22. http://dx.doi.org/10.1007/s12008-018-0460-1.

Reuter, C. 2015. Betriebliches Kontinuitätsmanagement in kleinen und mittleren Unternehmen-Smart Services für die Industrie 4.0. In Mensch und Computer 2015-Workshopband. https://doi. org/10.1515/9783110443905-006.

Rickmann, H. 2014. Verschläft der deutsche Mittelstand einen Megatrend? http://www.focus.de/finanzen/experten/rickmann/geringer-digitalisierungsgrad-verschlaeft-der-deutschemittelstand-einen-megatrend_id_3973075. html. Accessed on 10 Jan 2016.

Safar, L., J. Sopko, S. Bednar, and R. Poklemba. 2018. Concept of SME Business Model for Industry 4.0 Environment. TEM Journal 7 (3), 626. https://doi.org/10.18421/TEM73-20.

Schlegel, A., T. Langer, and M. Putz. 2017. Developing and Harnessing the Potential of SMEs for Eco-Efficient Flexible Production. Procedia Manufacturing 9: 41-48. https://doi.org/10.1016/j.promfg.2017.04.028.

SBA. 2018. Small Business Profile. https://www.sba.gov/sites/default/files/ advocacy/2018-Small-Business-Profiles-US.pdf. Accessed on 12 Jan 2019.

Scheidel, W., I. Mozgova, and R. Lachmayer. 2018. Teaching Industry 4.0Product Data Management For Small and Medium-Sized Ebterprises. Proceedings of the 20th International Conference on Engineering and Product Design Education (E\&PDE 2018) DS 93, 151-156. Dyson School of Engineering, Imperial College, London, 6th-7th September 2018.

Seidenstricker, S., E. Rauch, and P. Dallasega. 2017. Industrie-4.0Geschäftsmodell-innovation für KMU. ZWF Zeitschrift für wirtschaftlichen Fabrikbetrieb 112 (9), 616-620. https://doi.org/10.3139/104.111776.

Sendler, U. (ed.). 2013. Industrie 4.0: Beherrschung der industriellen Komplexität mit SysLM. Berlin and Heidelberg: Springer Vieweg. https:// doi.org/10.1007/978-3-642-36917-9_1. 
Sezer, E., D. Romero, F. Guedea, M. Macchi, and C. Emmanouilidis. 2018. An Industry 4.0-Enabled Low Cost Predictive Maintenance Approach for SMEs. In 2018 IEEE International Conference on Engineering, Technology and Innovation (ICE/ITMC), 1-8. https://doi.org/10.1109/ICE.2018.8436307.

Sommer, L. 2015. Industrial Revolution-Industry 4.0: Are German Manufacturing SMEs the First Victims of This Revolution? Journal of Industrial Engineering and Management 8 (5): 1512-1532. https://doi. org/10.3926/jiem.1470.

Spath, D., O. Ganschar, S. Gerlach, T.K. Hämmerle, and S. Schlund. 2013. Produktionsarbeit der Zukunft - Industrie 4.0. Stuttgart: Fraunhofer Verlag. ThaiEmbDC. 2019. https://thaiembdc.org/thailand-4-0-2/. Accessed on 10 Mar 2019.

Türkeș, M.C., I. Oncioiu, H.D. Aslam, A. Marin-Pantelescu, D.I. Topor, and S. Căpuşneanu. 2019. Drivers and Barriers in Using Industry 4.0: A Perspective of SMEs in Romania. Processes 7 (3): 153. https://doi. org/10.3390/pr7030153.

Ward. 2018. SME Definition (Small to Medium Enterprise). https://www. thebalancesmb.com/sme-small-to-medium-enterprise-definition-2947962. Accessed on 13 Mar 2019.

Weiß, M., M. Tilebein, R. Gebhardt, and M. Barteld. 2018. Smart Factory Modelling for SME: Modelling the Textile Factory of the Future. Lecture Notes. Business Information Processing 319: 328-337. https://doi. org/10.1007/978-3-319-94214-8_24.

Wiesner, S., P. Gaiardelli, N. Gritti, and G. Oberti. 2018. Maturity Models for Digitalization in Manufacturing-Applicability for SMEs. In IFIP International Conference on Advances in Production Management Systems, 81-88. Cham: Springer. https://doi.org/10.1007/978-3-319-99707-0_1.

Wölfel, C., U. Debitz, J. Krzywinski, and R. Stelzer. 2012. Methods Use in Early Stages of Engineering and Industrial Design-A Comparative Field Exploration. In Proceedings of DESIGN 2012, the 12th International Design Conference, Dubrovnik, Croatia DS 70.

WTO. 106. World Trade Report 2016. Levelling the Trading Field for SMEs. https://www.wto.org/english/res_e/booksp_e/world_trade_report16_e.pdf. Accessed on 15 Feb 2019.

Yoshino, N., and F. Taghizadeh-Hesary. 2018. The Role of SMEs in Asia and Their Difficulties in Accessing Finance. ADBI Working Paper 911. Tokyo: Asian Development Bank Institute. https:/www.adb.org/publications/rolesmes-asia-and-their-difficulties-accessing-finance. Accessed on 11 Feb 2019. 
Zambon, I., M. Cecchini, G. Egidi, M.G. Saporito, and A. Colantoni. 2019. Revolution 4.0: Industry vs. Agriculture in a Future Development for SMEs. Processes 7 (1): 36. https://doi.org/10.3390/pr7010036.

Zhou, J., P. Li, Y. Zhou, B. Wang, J. Zang, and L. Meng. 2018. Toward New-

Generation Intelligent Manufacturing. Engineering 4 (1): 11-20. https:// doi.org/10.1016/j.eng.2018.01.002.

Open Access This chapter is licensed under the terms of the Creative Commons Attribution 4.0 International License (http://creativecommons. org/licenses/by/4.0/), which permits use, sharing, adaptation, distribution and reproduction in any medium or format, as long as you give appropriate credit to the original author(s) and the source, provide a link to the Creative Commons license and indicate if changes were made.

The images or other third party material in this chapter are included in the chapter's Creative Commons license, unless indicated otherwise in a credit line to the material. If material is not included in the chapter's Creative Commons license and your intended use is not permitted by statutory regulation or exceeds the permitted use, you will need to obtain permission directly from the copyright holder.

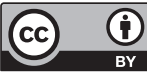

